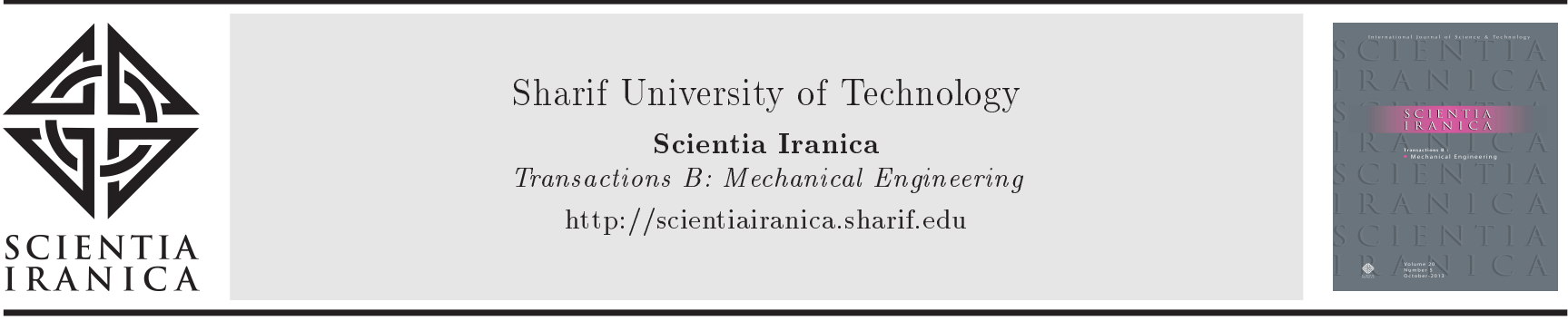

\title{
Investigation into the interaction between quartz nanostructures and human cell lines for tissue engineering
}

\author{
A. Shamloo*, M.A. Rad, M.T. Ahmadian, and L. Amirifar \\ Department of Mechanical Engineering, Sharif University of Technology, Tehran, Iran.
}

Received 17 June 2017; received in revised form 20 October 2018; accepted 17 June 2019

\section{KEYWORDS}

Quartz;

Nanotextured surface;

Cell;

Basement membrane;

Microfluidics;

PDMS.

\begin{abstract}
Control of interaction between nanostructures and living cells is important for tissue engineering. The topography and hydrophilicity of nanotextured surfaces can provide information on the in vitro interactions between cells and the surrounding environment, which is of great importance in bio-applications. This study proposes a Reactive Ion Etching (RIE) to texture the quartz surfaces with 5 and $10 \mathrm{~nm}$ surface roughness. The interaction of human cell lines (human breast cancer cells, MCF-7, and Human Dermal Micro-Vascular Endothelial Cells (HDMVEC)) with the nanostructured surfaces exhibited different levels of morphogenesis when the cells adhered to the bare and nanotextured quartz surfaces. The chemical compositions of the surfaces were characterized by X-ray Photoelectron Spectroscopy (XPS) and the results showed that cells preferred to grow on hydrophilic surfaces with hydroxyl groups. Moreover, the cellular processes, such as adhesion and spreading, were affected by the combination of physical and chemical properties of the surface, namely, surface topology and hydrophilicity. The findings demonstrated the potential applications of quartz nanostructure surfaces with high microscopic image quality in tissue engineering for controlling cell growth via appropriate surface modifications.

(C) 2020 Sharif University of Technology. All rights reserved.
\end{abstract}

\section{Introduction}

Biological cells adapt to their environment via their adhesive interaction with a substrate [1]. Since the cell adhesion phenomenon occurs before cell spreading, migration, and differentiation, the material surface interaction with the cells is very critical. There are several surface properties that affect cell adhesion, such as wettability, surface charge, surface roughness, and topography $[2-5]$. Therefore, various modifications

*. Corresponding author. Tel.: +982166165691

E-mail addresses: shamloo@sharif.edu (A. Shamloo);

Maryam.s.rad@gmail.com (M.A.Rad);

ahmadian@sharif.edu (M.T. Ahmadian);

leyla_amirifar@mech.sharif.edu (L.Amirifar)

doi: $10.24200 /$ sci. 2019.21464 can be made to improve surface characteristics of the materials.

The surface of substrates can be modified through different techniques involving changing the surface chemistry and/or topography. These techniques include physical methods, such as plasma treatment with glow or corona discharge [6] and ion beam irradiation [7]. Surface etching and grafting methods [811] are employed for chemical modifications. The plasma treatment process in various gas environments generates numerous types and quantities of functional groups on the substrate, which can be controlled via gas composition, distance between the samples and the electrode, and power and duration of plasma treatment $[12,13]$. Plasma etching and nanotexturing can change the topography of surfaces to induce preferential cell adhesion in predefined areas [14-18]. 
Micro/nanotextured structures have the size of ECM proteins, hence they affect cells directly $[19,20]$. Microstructured surfaces alter cell morphology [21], while nanostructured substrates can induce proliferation and differentiation [22].

Behavior of diverse cell types in response to surfaces with nanotopography has been widely investigated. Human fetal osteoblastic (hFOB) cells cultured on plasma treated polystyrene films [23], mouse immortalized fibroblasts cell line (3T3) cultured on oxygen plasma etched Poly Methyl Methacrylate (PMMA) substrates [24], Vascular Smooth Muscle Cells (VSMCs) and mouse fibroblasts (L929) cultured on plasma modified polyethylene [25], neuronlike PC12 cells cultured on micro reactive ion etched nanotextured glass coverslips [26], rat mast cell line (RBL-2H3) cultured on chemically etched titanium surfaces [27], and mouse neuronal Schwann cell line (SW10) cultured on laser micro/nano structured silicon surfaces [28] all represent enhanced adhesion, proliferation, and migration.

Cancer cell isolation and culture on nanotextured surfaces have been studied as well [29]. In order to capture MCF-7 cells, a wet chemical etching method was used on silicon wafers to achieve nanopillars (SiNP) with diameters in the range of 100-200 nm [30]. The nanostructured surfaces were coated with epithelialcell adhesion molecule antibody (anti-EpCAM) and the results exhibited capture yield of cancer cells up to 10 times more than the flat silicon substrates. In another study, Islam et al. [31] fabricated nanotextured polydimethylsiloxane (PDMS) substrates using micro Reactive Ion Etching (RIE) modified with immobilized aptamers. It was shown that the growth rate of human glioblastoma cells was higher on these surfaces than on plain PDMS. A nano-electromechanical chip (NELMEC) was introduced by Hosseini et al. [32] to distinguish both epithelial and mesenchymal circulating tumor cells, MCF-7 and MDA-MB231 cell lines respectively, from white blood cells through a labelfree method. In this microfluidic device, tumor cells were captured by silicon nanograss (SiNG) electrodes based on their various membrane capacitance and the capture yields were between $92 \%$ to $97 \%$. Dou et al. [33] developed bioinspired micro and nanotextured PDMS surfaces with hierarchical topographies of the rose petals to capture and release circulating tumor cells (PaTu 8988t and MCF7). Anti-EpCAM was conjugated to the surfaces for better cell-targeting. They achieved capture ability 6 times higher than that of flat surfaces, even at low concentration of 100 cell $\mathrm{mL}^{-1}$, and efficient release of captured cells with high viability for the subsequent cell analysis.

Polymers [34,35], metals [36,37], and glass/quartz $[26,38,39]$ are commonly used as substrates for nanotexturing. Among these materials, bare glass/quartz substrate is considered as a suitable candidate for cell culture experiments, because it provides satisfactory optical properties, low auto-fluorescence in the UV range, and negligible or lack of birefringent properties that can deteriorate microscopic image quality [4042]. Glass/quartz is also chemically inert compared to transparent plastic cover slip. Poly-L-lysine, laminin, fibrillin, fibronectin, collagen, and other components are used as substrate coatings to enhance cell adhesion, but they may interfere with the cell spectra $[43,44]$. Draux et al. [45] compared three substrates used for Raman microspectroscopy (Quartz, ZnSe, and CaF2) of cancer cells. This study revealed that quartz and $\mathrm{CaF} 2$ were more suitable for cell growth than ZnSe, which showed weak cell adherence because of its toxicity. No cytotoxic properties of glass/quartz substrates were observed for cell adhesion and proliferation $[46,47]$. However, quartz exhibits superior optical and thermal properties to other kinds of glass due to its purity.

In this work, cell adhesion and its growth behavior were investigated on bare and nanotextured quartz surfaces in a microfluidic platform. Adult Human Dermal Micro-Vascular Endothelial Cell (HDMVEC) line, as the representative of normal cells, and human breast cancer cell line (MCF-7), as representative of tumor cells, were evaluated in this study. These two types of cells were chosen due to the increasing prevalence of vascular diseases and cancer. In addition, they provided the possibility of comparison between the behaviors of healthy and unhealthy cells. Examining the aforementioned cell types showed the versatility of our proposed microfluidic device. The quartz surface was nanotextured by RIE system. Then, PDMS microfluidic channels were integrated with nanotextured quartz surfaces to investigate cell adhesion strength. Based on Atomic Force Microscopy (AFM) and X-ray Photoelectron Spectroscopy (XPS) results, roughness and hydrophilicity of the nanostructured quartz surfaces increased, respectively. Results indicated that the nanotextured quartz surface was a more suitable platform for controlling the adhesion of HDMVECs than that of MCF-7 cells. In addition, the nanotextured quartz surfaces had high-quality microscopic images for biological application. Combination of nanotexturing and microfluidic technology can inspire researchers to simulate biological processes in vitro and understand cellular behavior in vivo.

\section{Materials and methods}

\subsection{Fabrication of nanotextured quartz surfaces}

In the process of experiments, $0.5 \mathrm{~mm}$ thick quartz substrates were rinsed with acetone and isopropyl alcohol (IPA) in an ultrasonic cleaning bath for $20 \mathrm{~min}$ 
and washed in a flow of deionized water and blown with air. The RIE process was employed with Sulphur hexafluoride $\left(\mathrm{SF}_{6}\right)$ and Ar gases mixture to texture the quartz surfaces. The etching process was performed with the power of $200 \mathrm{~W}$ and pressure of $20 \mathrm{mTorr}$ for 25 and 30 minutes. The flow rates of $\mathrm{SF}_{6}$ and Ar gas were both $25 \mathrm{sccm}$.

\subsection{Fabrication of microfluidic channel with $S U-8$ mold}

In this work, the PDMS microchannel was constructed via soft lithography method. Schematic illustrations of the fabrication process of PDMS/quartz microfluidic device are shown in Figure 1. The fabrication processes involved mold fabrication and PDMS (Sylgard 184 silicone elastomer base) casting. The silicon master mold was fabricated through photolithography process. To prepare the PDMS, the elastomer base was mixed with curing agent at a ratio of 10:1 in weight. The mixture was degassed in a vacuum chamber and then, casted onto the Si master mold. This was followed by curing it at $125^{\circ} \mathrm{C}$ for $20 \mathrm{~min}$. The PDMS replica was then peeled off from the mold. Two holes were punched on the reservoirs to make the inlet and outlet for PDMS microfluidic device. Consequently, PDMS microfluidic channel with dimensions of $300 \mu \mathrm{m}$ in width and $80 \mu \mathrm{m}$ in height was fabricated.

To bond a PDMS microchannel to a quartz surface, they were treated in air plasma for $30 \mathrm{~s}$. Then, the PDMS microchannel and quartz substrates (treated and untreated) were brought into contact with each other and hardly pressed to make a permanent seal. The fabricated device was heated for 5-10 minutes to strengthen the bonding. Prior to use, the device was sterilized with UV light for $30 \mathrm{~min}$.

\subsection{Atomic Force Microscopy (AFM)}

The Root Mean Square (RMS) roughness of the quartz substrates was acquired at room temperature using AFM to evaluate the surface morphology. The RMS roughness of samples was obtained by the scanned areas acquired using AFM topographies.

\subsection{Transmittance measurement}

To investigate optical performance, the transmittance was measured for the nanostructured quartz using a UV-visible spectrometer (ReyLeigh UV-2601). The measurement was performed in the range of $200 \mathrm{~nm}$ to $1000 \mathrm{~nm}$.

\subsection{X-ray Photoelectron Spectroscopy (XPS) measurement}

The effect of plasma etching on the chemical structure of quartz surface was analyzed using XPS (BESTEC, Germany). The results were measured using an analyzer equipped with a monochromatic Al-K $\alpha$ Xray source $(h \nu=1486.6 \mathrm{eV})$ operating at ultra-high vacuum $\left(10^{-7} \mathrm{~Pa}\right)$.

\subsection{Scanning Electron Microscopy (SEM) samples preparation}

The cells were cultured on the untreated and nanotextured quartz surfaces for $12 \mathrm{~h}$ under normal conditions, as described in the following. After incubation, cells were washed with Phosphate Buffered Saline (PBS) and fixed with $2.5 \%$ glutaraldehyde for $5 \mathrm{~h}$ at $4^{\circ} \mathrm{C}$. The cells were washed again three times with PBS; treated with different grades of ethanol $(50 \%, 70 \%, 95 \%$, and $100 \%$ ) twice, 10 min each; and dewatered with acetone, followed by air flow drying. SEM images of cells were obtained using acceleration voltage of $20 \mathrm{kV}$. Prior

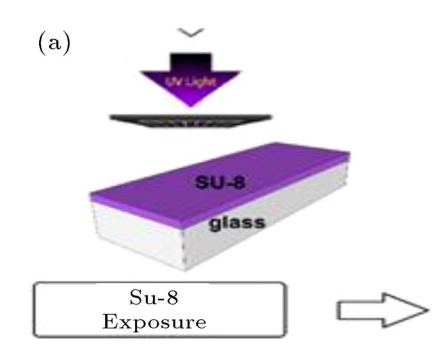

(b)

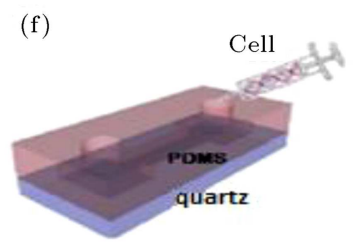

Bonding of

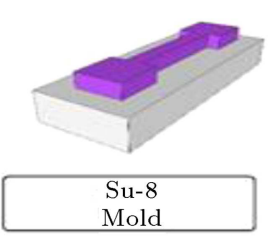

(e)

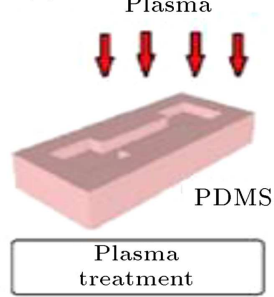

Mixture of PDMS

(c) prepolymer \& curing agent

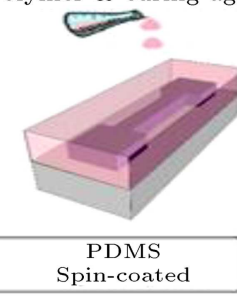

(d)

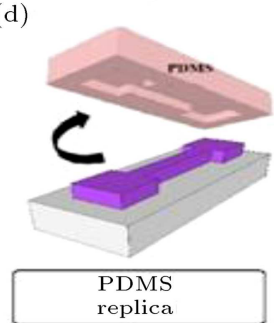

Figure 1. Schematics of the fabrication process of Polydimethylsiloxane (PDMS)/quartz microfluidic device. 
to measurement, the samples surfaces were coated by $20 \mathrm{~nm} \mathrm{Au}$ to prevent charging effects.

\subsection{Cell culture}

Both endothelial and MCF-7 cells were obtained from National Cell Bank of Pasteur Institute of Iran [48]. The endothelial cells were cultured in Dulbecco's Modified Eagle's Medium (DMEM)/F-12, which contained $5 \%$ horse serum, $100 \mathrm{Uml}^{-1}$ penicillin, $100 \mu \mathrm{g} \mathrm{ml}^{-1}$ streptomycin, $100 \mathrm{ng} \mathrm{ml}^{-1}$ cholera toxin, $10 \mathrm{ng} \mathrm{ml}^{-1}$ epidermal growth factor, $0.5 \mathrm{mg} \mathrm{ml}^{-1}$ hydrocortisone, $10 \mathrm{mg} \mathrm{ml} \mathrm{m}^{-1}$ insulin, and $1 \%(w / v)$ L-glutamine at $37^{\circ} \mathrm{C}$ under an atmosphere of $5 \% \mathrm{CO}_{2}$ (all from Sigma Chemical). Similarly, MCF-7 cells were cultured in DMEM containing $10 \% \mathrm{FBS}, 100 \mathrm{U} \mathrm{ml}^{-1}$ penicillin, $100 \mu \mathrm{g} \mathrm{ml}^{-1}$ streptomycin, $10 \mathrm{mg} \mathrm{ml}^{-1}$ insulin, and $1 \%(w / v)$ L-glutamine.

For cell culturing in the microchannel, the cells were treated with $0.25 \%$ trypsin-EDTA and washed with FBS three times to eliminate the trypsin trace. Cell concentration was controlled at $\sim 2.5 \times 10^{6} \mathrm{ml}^{-1}$ to provide consistent experimental conditions. For measuring the cell adhesion, each cell solution was injected into the microchannel by surface tension driven capillary flow. Consequently, after stopping the injection, the cells were left to adhere to the bottom of the microchannel in an incubator for 12 hours. Then, bright-field images of cells were taken under optical microscope (Labomed, TCM 400). To have a uniform shear stress, cells were spread homogeneously with an appropriate spacing between them. Next, by connecting each microchannel to a syringe pump, the medium solution was transferred into the microchannel with raising flow rate in a stepwise manner. In each step, the medium was flowed for the time span of $60 \mathrm{sec}$ and the number of adherent cells was counted through an optical microscope.

\subsection{MTT assay}

MTT assay is a colorimetric assay showing the viability of the live species to remain alive while exposed to a certain environment [49]. The nanotextured quartz surfaces were made sterile by autoclave before cell seeding process. As a control, an equivalent volume of cells was cultured into a culture dish. The attached cells viability on the nanotextured quartz surfaces was investigated in 3-(4,5 dimethylthiazol-2-yl)-2,5diphenyltetrazolium bromide (MTT) assay conditions. For this purpose, the cells were cultured for 12 hours as explained in Section 2.5. Then, the substrate samples were transferred to a well with cells and $10 \mu \mathrm{l}$ of MTT solution with the concentration of $5 \mathrm{mg} / \mu \mathrm{l}$ was added to the each well. Then, for a duration of four hours, MTT was allowed to be metabolized by cells at $37^{\circ} \mathrm{C}$ in $5 \% \mathrm{CO}_{2}$. Then, the float materials were carefully removed from the surface of the wells and $400 \mu \mathrm{l}$ of dimethyl sulfoxide (DMSO) was added to each well. The wells were shaken for $10 \mathrm{~min}$ and the Optical Density (OD) of the dissolved solute was acquired at $560 \mathrm{~nm}$ wavelength, with $670 \mathrm{~nm}$ reflected.

\subsection{Statistical analysis}

The SPSS statistical software version 18 was used to investigate the results. All the data in this research were shown as means \pm the standard error of the mean and analyzed using single-factor ANOVA. In addition, the significance level was established at $P<0.05$. The means ( $+\mathrm{SD})$ of three biological replicates are reported here.

\section{Results and discussion}

\subsection{Quartz analysis}

\subsubsection{AFM analysis}

The AFM topology of the untreated and nanostructured quartz surfaces is presented in Figure 2. The RIE process conditions are described in Section 2.1. The average of the measured roughness of the untreated quartz is $0.5 \mathrm{~nm}$, whereas those of the samples textured for 25 and $30 \mathrm{~min}$ are 5 and $10 \mathrm{~nm}$, respectively.

\subsubsection{Transmittance analysis}

Transmittance was measured for the treated quartz samples from UV to the near-IR region (200 nm to $2000 \mathrm{~nm}$ ). (Figure 3). Transmission data for a bare quartz sample were used as reference. The

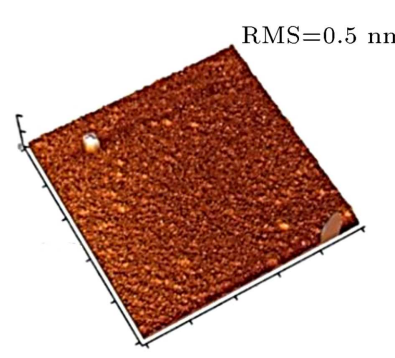

(a)

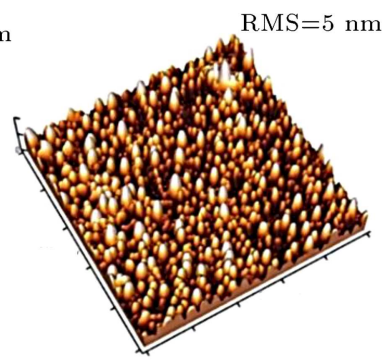

(b)

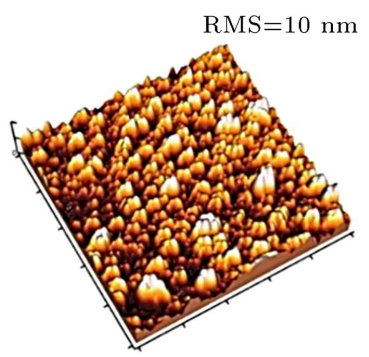

(c)

Figure 2. Atomic Force Microscopy (AFM) images of quartz samples: (a) Before plasma treatment and after (b) 25 min, and (c) 30 min plasma treatment. 


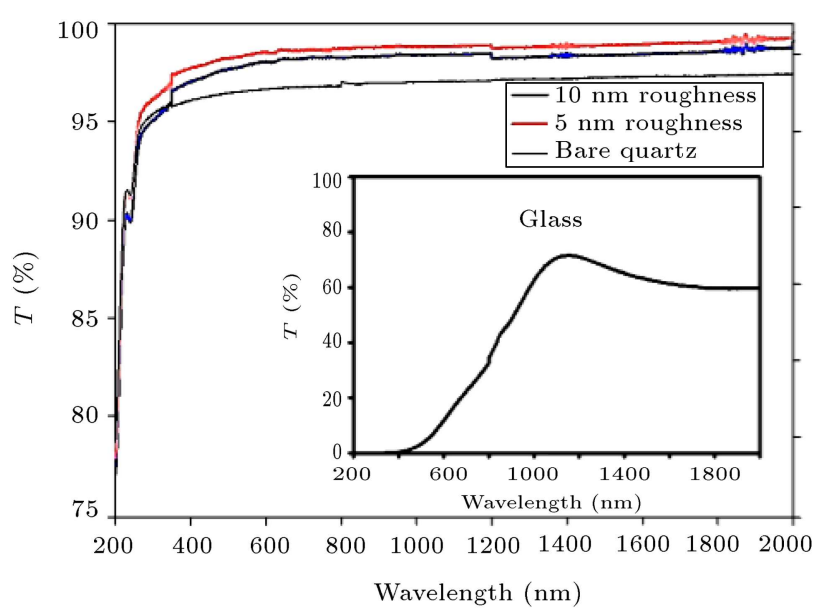

Figure 3. Transmittance spectra of the quartz and glass samples.

nanostructured quartz surfaces with 5 and $10 \mathrm{~nm}$ roughness had very similar curves to that of the bare surface, because the height of nanostructures was very short. In addition, it is clear from Figure 3 that quartz has higher transmission than the glass substrate and, most importantly, it is transparent in the broad range. Thereby, the microscopic image quality of the biological samples being viewed via modified quartz substrate has improved.

\subsubsection{XPS analysis}

The curve in Figure 4 shows the XPS profiles in highresolution $\mathrm{Si} 2 \mathrm{p}$ area for untreated and treated quartz surfaces with 5 and $10 \mathrm{~nm}$ of roughness. The determined value for Binding Energy (BE) of Si $2 p$ electrons $(B E=103.9 \mathrm{eV})$ in this work is in agreement with the reported one for the natural quartz [50]. The value is almost equivalent to $\mathrm{SiO}_{2}$ and corresponds to the $\mathrm{Si}^{4+}$ oxidation state. By contrast, the $\mathrm{BE}$ of the $\mathrm{Si} 2 \mathrm{p}$ core level of the treated quartz samples is $105 \mathrm{eV}$, as shown in Figure 4. The energy shift of the XPS peaks to $105 \mathrm{eV}$ is possible because of the formation of $\mathrm{SiO}_{x} \mathrm{~F}_{y}$ passivation layer during RIE process. Also, we can see from this figure that the $\mathrm{Si}(-\mathrm{OH})_{x}$ peak at $102.5 \mathrm{eV}$ occurred after RIE process. In fact, the quartz surface was activated by argon plasma and the introduced groups to the surface. The activated surface can react with the oxygen or moisture in the air, forming Si$\mathrm{OH}$ groups on the quartz surface $[51,52]$. Based on our XPS results, hydrophilic functional groups and hydrophilicity of the quartz surface increases.

\subsection{Cell analysis}

\subsubsection{SEM analysis}

The substrate is a support for cells with specific physical and chemical properties to guide cellular behavior. The initial indicator of cell interaction with its microenvironment is adhesion through mechanotrasduction [53]. Focal adhesions, which are large

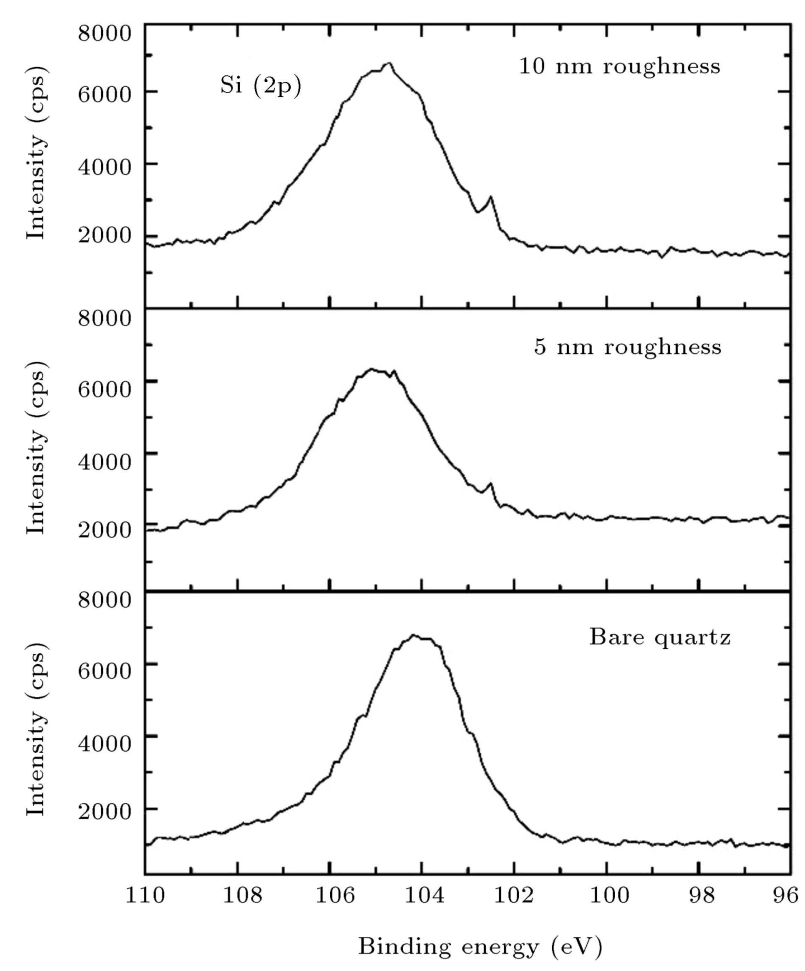

Figure 4. Comparison of Si (2p) X-ray Photoelectron Spectroscopy (XPS) spectra acquired on untreated and treated quartz surfaces.

macromolecular integrin-containing structures, receive extracellular mechanical signals and transduce them to intracellular forces and chemical signals. As a result, a traction force is generated on the cytoskeleton and then, exerted on the substrate during adhesion. Following adhesion, cells start to adapt to their surrounding environment, leading to spreading, migration, and differentiation $[54,55]$.

Figure 5 shows the SEM images of MCF-7 and endothelial cells after $12 \mathrm{~h}$ of culture on untreated and nanostructured quartz surfaces with 5 and $10 \mathrm{~nm}$ surface roughness. The SEM images revealed that both cell types had an almost spherical form on the untreated quartz surfaces (Figure 5(a) and (b)). However, in Figure 5(b), the connection of endothelial cell indicates larger adhesion strength to the surface than the cancer cell. Cells in vivo interact with complex nanoscale structures, not plain surfaces. Thus, nanotexturing mimics the extracellular matrix of various tissues providing natural cell behavior. Nanotextured surfaces regulate cell function by inducing local differences in interfacial forces followed by changes in focal adhesion formation and cytoskeletal structure [56]. Figure 5(c) and (d) show that increasing surface roughness to $5 \mathrm{~nm}$ enhances the adhesion strength of both cells. Nanostructured quartz surfaces with $10 \mathrm{~nm}$ roughness led to the elongation of MCF-7 cells in a triangular manner (Figure 5(e)). In general, cancer cells are symmetrically star-shape 


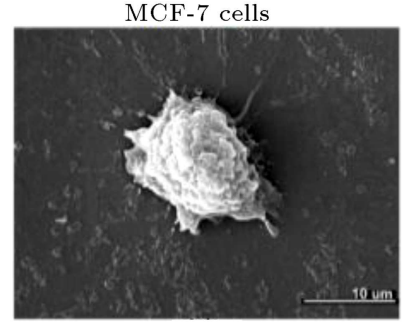

(a)

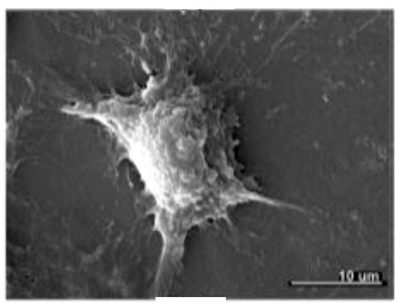

(c)

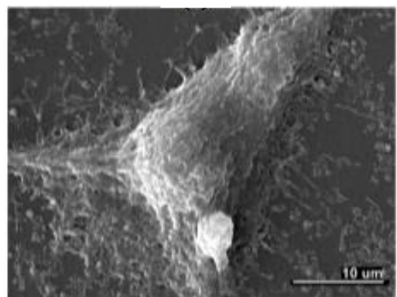

(e)
Endothelial cells

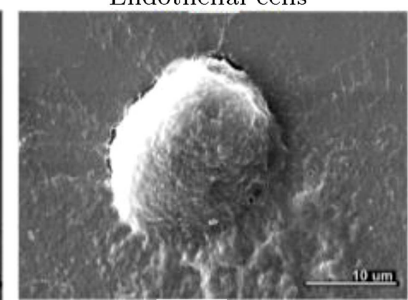

(b)

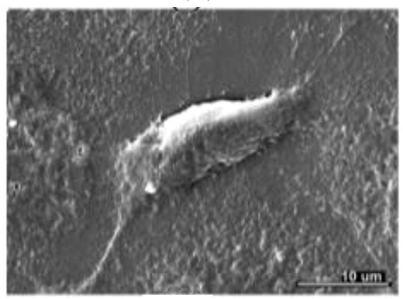

(d)

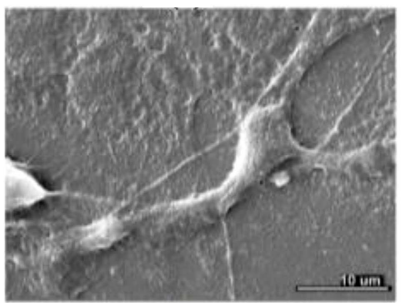

(f)

Figure 5. Scanning Electron Microscopy (SEM) images of MCF-7 and endothelial cells after 12 hours of cell culture in an incubator on $((a),(b))$ untreated quartz surface, ((c), (d)) nanotextured quartz surfaces with a roughness of $5 \mathrm{~nm}$, and ((e), (f)) $10 \mathrm{~nm}$.

structures on the nanostructured quartz surfaces, whereas endothelial cells have irregular structures [57]. Lamellipodia associated with endothelial cells is spread widely on the surface, even at low surface roughness, which is not much visibly detectable in MCF-7 cells (Figure 5(f)). It is shown that the number of filopodia in both cancer and endothelial cells increases with increase in the surface roughness [58]. Naturally, endothelial cells tend to grow attached to the substrate, while cancer cells prefer to grow spherically and in the form of a tumor. Our results support this fact as the adherence and elongation of MCF-7 cells are not pronounced very well onto the nanostructured quartz surfaces compared with the endothelial cells.

Substrate modification not only has impact on cell deformation, but also changes the nuclear shape $[59,60]$. It is observed that the deformation of cancer cell nuclei is different from that of healthy cells [61]. This difference highlights the potential of micro/nanotextured substrates for cancer cell identification and isolation.

\subsubsection{Cell viability}

Biocompatibility of the nanotextured quartz surfaces was investigated by MTT assays. Figure 6 shows the viability of the seeded MCF-7 and endothelial cells

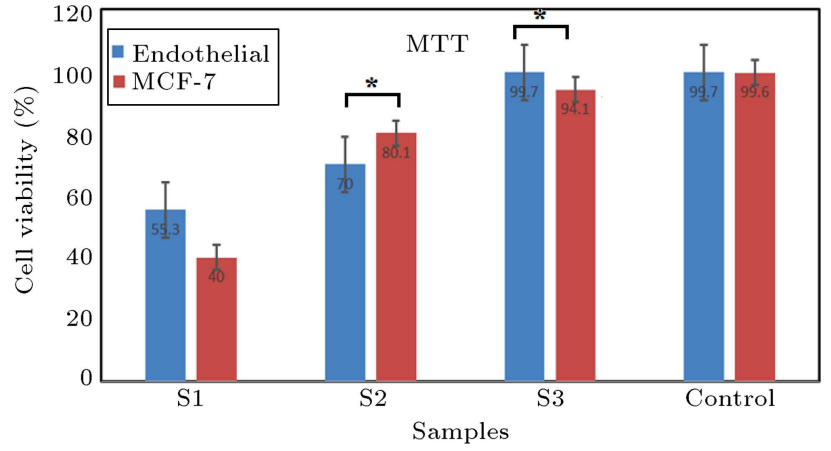

Figure 6. Viability measurement of MCF-7 and endothelial cells in response to different substrates - MTT test. $*=P<0.05$ relative to sample $\mathrm{S} 1$.

after $12 \mathrm{~h}$ of culture on the untreated quartz (S1), nanotextured quartz (S2, $5 \mathrm{~nm}$ roughness), nanotextured quartz (S3, $10 \mathrm{~nm}$ roughness), and control (culture flasks). The error bars illustrate mean $\pm S D$ of the data from three independent identical experiments. The cell viability differences were assessed. The results showed that cell viability percentage for untreated quartz (S1) was lower than that for the treated samples. No cytotoxic properties for cell adhesion and proliferation in glass/quartz substrates have been observed in previous studies $[46,47]$. Thus, most of the cells were probably detached from the bare (untreated) quartz surface during washing in MTT assay. The presented MTT results indicated that $97 \%$ of the endothelial cells and $94 \%$ of the MCF- 7 cells that adhered to the S3 surface remained alive. The results also showed that the viability of both cell types cultured on nanotextured surfaces with high roughness was not significantly different from that of the control. Therefore, our nanotextured platform provides a substrate with the desired properties of culture flasks, which is suitable for cell function. In general, almost all the endothelial cells were alive after $12 \mathrm{~h}$ of culture on the nanotextured quartz surface with $10 \mathrm{~nm}$ roughness (S3).

\subsubsection{Cell proliferation}

Figure $7(\mathrm{a})-(\mathrm{f})$ displays microscopic images of $\mathrm{MCF}-7$ and endothelial cells after $12 \mathrm{~h}$ of culture on untreated and treated quartz surfaces. As can be seen, the proliferation of both MCF-7 and endothelial cells was enhanced by increasing the quartz surface roughness. According to SEM images, MTT assay results, and microscopic images represented in this study, cells adhered, survived, and proliferated better as the quartz surface roughness increased to $10 \mathrm{~nm}$. In Figure $7(\mathrm{~g})$, the fraction of adherent MCF-7 and endothelial cells is plotted as a function of roughness variations. The fraction of MCF-7 adherent cells is higher than that of endothelial cells on the untreated quartz surface. As shown in this plot, the fraction of adherent cells for both MCF-7 and endothelial cells increases with 


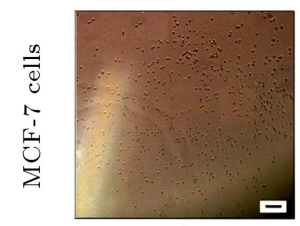

(a)

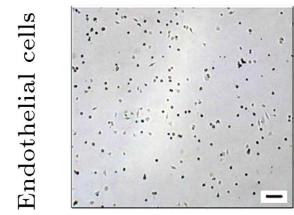

(d)

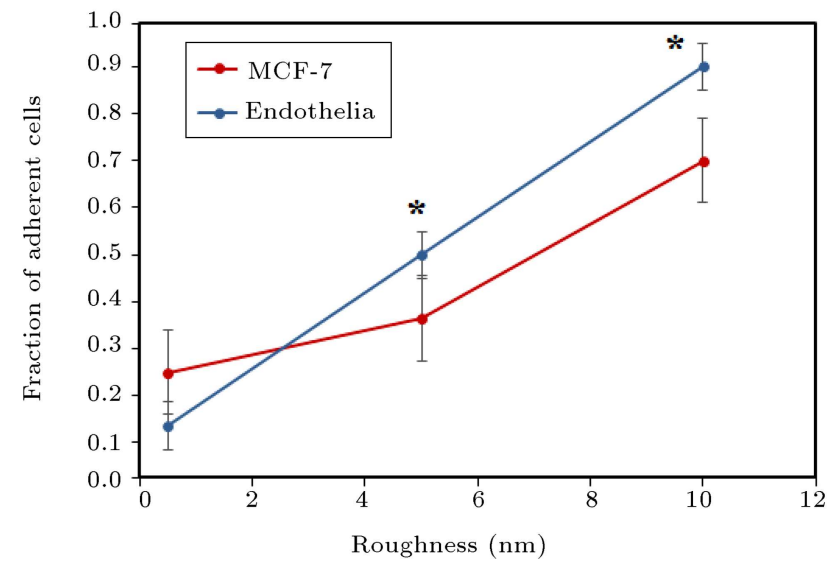

(g)
Figure 7. Microscopy images of MCF-7 and endothelial cells after $12 \mathrm{~h}$ culturing on ((a), (d)) untreated, ((b), (e)) $5 \mathrm{~nm}$-rough, and ((c), (f)) $10 \mathrm{~nm}$-rough surfaces (scale bars indicate $100 \mu \mathrm{m})$. (g) Plotted fraction of adherent MCF-7 and endothelial cells as a function of roughness (the cells demonstrated a significant adhesion by increasing the surface roughness compared with the untreated sample $(*=p<0.05))$.

increase in surface roughness up to $10 \mathrm{~nm}$. The fractions of MCF-7 and endothelial adherent cells are about 0.7 and 0.9 , respectively. Based on these observations, the rough surface affects endothelial cells more significantly and improves their adhesion to the surface. This result was more amplified at the roughness of $10 \mathrm{~nm}$. It should be noted that a saturation state was observed on very rough nanotextured surfaces, which led to cell inhibition at long cell culture times [24,62]. Thus, characteristics of nanotextured surfaces are to be optimized according to the desired application.

\subsubsection{Cells in PDMS microfluidic channel}

To examine the adhesion strength of MCF-7 and endothelial cells, a PDMS-based microfluidic channel was fabricated on the quartz surfaces. Figure 8(a) and (b) shows the MCF-7 and endothelial cells in a PDMS microfluidic device after $12 \mathrm{~h}$ of culture on untreated quartz surfaces. The cells remained spherical and unstretched on the untreated quartz surfaces in
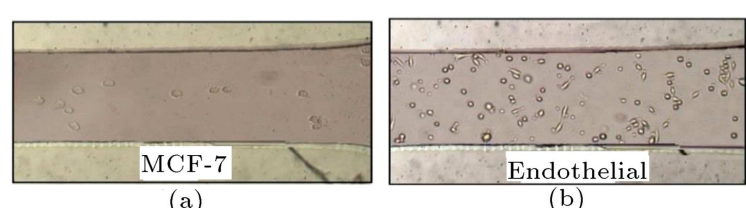

(a)
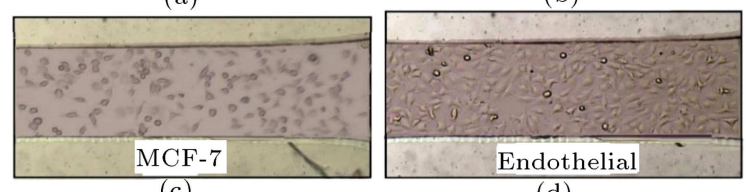

(c)

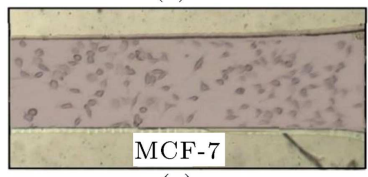

(e)
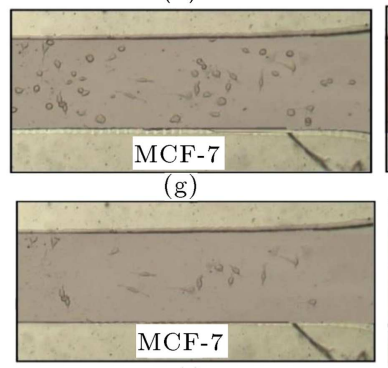

(i)

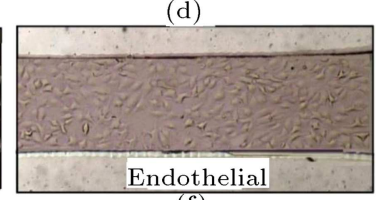

(f)

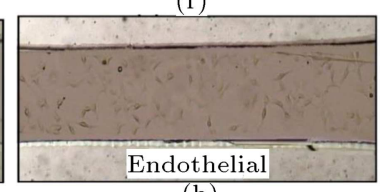

(h)

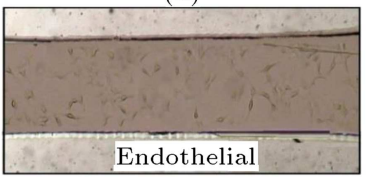

(j)

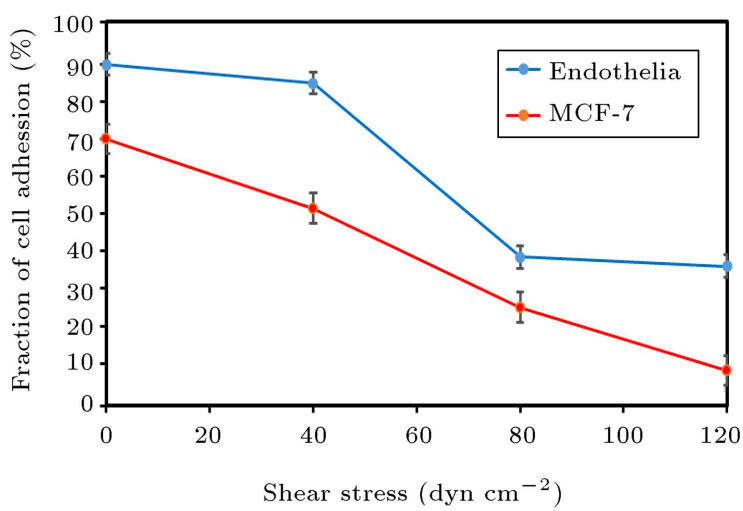

(k)

Figure 8. MCF-7 and endothelia cells after $12 \mathrm{~h}$ culturing in the PDMS/quartz microfluidic device on ((a), (b)) untreated surface with no shear stress, ((c), (d)) $10 \mathrm{~nm}$ rough surface with no shear stress, ((e), (f)) $10 \mathrm{~nm}$ rough surface with the shear stress of 40 dyn $\mathrm{cm}^{-2},((\mathrm{~g})$, (h) $10 \mathrm{~nm}$ rough surface with the shear stress of 80 dyn $\mathrm{cm}^{-2}$, and ((i), (j)) $10 \mathrm{~nm}$ rough surface with the shear stress of $120 \mathrm{dyn} \mathrm{cm}^{-2}$. (k) Fraction of MCF-7 and endothelial cells remaining adherent to nanorough $(\mathrm{RMS}=10 \mathrm{~nm})$ substrates after $6 \mathrm{~min}$ exposure to constant directional fluid shear.

the microfluidic device. Ten nm rough quartz surface proved the best choice for cell culture. Therefore, in the next step of our study, the microfluidic device was fabricated based on this roughness. Figure 8(c) and (d) shows the MCF-7 and endothelial cells in the microchannel with $10 \mathrm{~nm}$ rough quartz surface 
device after $12 \mathrm{~h}$ of culture. Increasing the surface roughness enhanced cell attachment and proliferation for both cancer and endothelial cells. In addition, fluid shear stress was applied to the microfluidic channel with $10 \mathrm{~nm}$ roughness and the stress increased from 0 to 120 dyn $\mathrm{cm}^{-2}$ within $6 \mathrm{~min}$ (Figure $8(\mathrm{e})-(\mathrm{j})$ ). The results indicated meaningfully different levels of preference between MCF-7 and endothelial cells in adhering to the nanorough quartz surface. Fractions of MCF-7 and endothelial cells that were attached to the untreated and nanorough surfaces were quantified and they are plotted in Figure $8(\mathrm{k})$. It was observed that the endothelial cells which adhered to the rough surfaces could resist higher fluidic shear stress than $\mathrm{MCF}-7$ cells. In fact, only $8 \%$ of MCF-7 cells remained in the microfluidic channel and $92 \%$ of them detached from

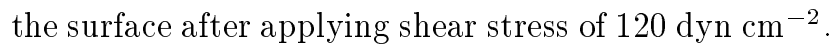
By contrast, $36 \%$ of the endothelial cells remained attached to the surface of the microchannel. This finding suggests that endothelial cells are more adhesive to the nanorough surfaces than MCF-7 cells are.

\section{Conclusion}

Quartz substrates were successfully nanotextured by Reactive Ion Etching (RIE) process to modify the surface properties for tissue engineering. The quartz nanotextured surfaces were attached to a Polydimethylsiloxane (PDMS) microchannel to fabricate a microfluidic device for dynamic cell culture. Plasma-treated surfaces offered improved cell adhesion, allowing cell growth, spreading, and proliferation and demonstrating biocompatibility of the samples. The Scanning Electron Microscopy (SEM) and MTT test results demonstrated that endothelial cells exhibited superior adhesion and proliferation to MCF-7 cells. Moreover, the sheer stress effect in the microfluidic devices led to higher adhesion strength in endothelial cells. The findings indicated that the proposed technique can be used for surface nanotexturing in investigating the adhesion and growth of cancer cells on nano-scale surfaces. Consequently, it can also be used to develop cell cultures for applications such as drug delivery, cancer cell biology, and tissue engineering.

\section{Acknowledgements}

The authors gratefully acknowledge the financial support from the Iran National Science Foundation (INSF).

\section{References}

1. Shamloo, A., Mohammadaliha, N., and Mohseni, M. "Integrative utilization of microenvironments, biomaterials and computational techniques for advanced tissue engineering", Journal of Biotechnology, 212, pp. 71-89 (2015).

2. Chen, W., Villa-Diaz, L.G., Sun, Y., et al. "Nanotopography influences adhesion, spreading, and selfrenewal of human embryonic stem cells", ACS Nano, 6, pp. 4094-4103 (2012).

3. Smith, I.O., Liu, X.H., Smith, L.A., et al. "Nanostructured polymer scaffolds for tissue engineering and regenerative medicine", Wiley Interdisciplinary Reviews: Nanomedicine and Nanobiotechnology, 1, pp. 226-236 (2009).

4. Limongi, T., Tirinato, L., Pagliari, F., et al. "Fabrication and applications of micro/nanostructured devices for tissue engineering", Nano-Micro Letters, 9, p. 1 (2016).

5. Yang, S.-P., Wen, H.-S., Lee, T.-M., et al. "Cell response on the biomimetic scaffold of silicon nano- and micro-topography", Journal of Materials Chemistry B, 4, pp. 1891-1897 (2016).

6. Liu, Z.-M., Tingry, S., Innocent, C., et al. "Modification of microfiltration polypropylene membranes by allylamine plasma treatment: Influence of the attachment route on peroxidase immobilization and enzyme efficiency", Enzyme and Microbial Technology, 39, pp. 868-876 (2006).

7. Xu, X., Kwok, R.W.M., and Lau, W.M. "Surface modification of polystyrene by low energy hydrogen ion beam", Thin Solid Films, 514, pp. 182-187 (2006).

8. Guo, L., Kawazoe, N., Fan, Y., et al. "Chondrogenic differentiation of human mesenchymal stem cells on photoreactive polymer-modified surfaces", Biomaterials, 29, pp. 23-32 (2008).

9. Kondyurin, A., Gan, B.K., Bilek, M.M.M., et al. "Etching and structural changes of polystyrene films during plasma immersion ion implantation from argon plasma", Nuclear Instruments and Methods in Physics Research Section B: Beam Interactions with Materials and Atoms, 251, pp. 413-418 (2006).

10. Hu, Y., Winn, S.R., Krajbich, I., et al. "Porous polymer scaffolds surface-modified with arginine-glycineaspartic acid enhance bone cell attachment and differentiation in vitro", Journal of Biomedical Materials Research Part A, 64A, pp. 583-590 (2003).

11. Hamerli, P., Weigel, T., Groth, T., et al. "Surface properties of and cell adhesion onto allylamine-plasmacoated polyethylenterephtalat membranes", Biomaterials, 24, pp. 3989-3999 (2003).

12. Liu, Z.-M., Xu, Z.-K., Wan, L.-S., et al. "Surface modification of polypropylene microfiltration membranes by the immobilization of poly(N-vinyl-2-pyrrolidone): a facile plasma approach", Journal of Membrane Science, 249, pp. 21-31 (2005).

13. Hamerli, P., Weigel, T., Groth, T., et al. "Enhanced tissue-compatibility of polyethylenterephtalat membranes by plasma aminofunctionalisation", Surface and Coatings Technology, 174-175, pp. 574-578 (2003). 
14. Di Mundo, R., Nardulli, M., Milella, A., et al. "Cell adhesion on nanotextured slippery superhydrophobic substrates", Langmuir, 27, pp. 4914-4921 (2011).

15. Islam, M., Motasim Bellah, M., Sajid, A., et al. "Effects of nanotexture on electrical profiling of single tumor cell and detection of cancer from blood in microfluidic channels", Scientific Reports, 5, p. 13031 (2015).

16. Tsougeni, K., Tserepi, A., Boulousis, G., et al. "Control of nanotexture and wetting properties of polydimethylsiloxane from very hydrophobic to superhydrophobic by plasma processing", Plasma Processes and Polymers, 4, pp. 398-405 (2007).

17. Lopacinska, J.M., Gradinaru, C., Wierzbicki, R., et al. "Cell motility, morphology, viability and proliferation in response to nanotopography on silicon black", Nanoscale, 4, pp. 3739-3745 (2012).

18. Tsougeni, K., Tserepi, A., Constantoudis, V., et al. "Plasma nanotextured PMMA surfaces for protein arrays: Increased protein binding and enhanced detection sensitivity", Langmuir, 26, pp. 13883-13891 (2010).

19. Bettinger, C.J., Langer, R., and Borenstein, J.T. "Engineering substrate topography at the microand nanoscale to control cell function", Angewandte Chemie International Edition, 48, pp. 5406-5415 (2009).

20. Hasirci, V. and Pepe-Mooney, B.J. "Understanding the cell behavior on nano-/micro-patterned surfaces", Nanomedicine, 7, pp. 1375-1389 (2012).

21. Badique, F., Stamov, D.R., Davidson, P.M., et al. "Directing nuclear deformation on micropillared surfaces by substrate geometry and cytoskeleton organization", Biomaterials, 34, pp. 2991-3001 (2013).

22. Lee, K.Y., Alsberg, E., Hsiong, S., et al. "Nanoscale adhesion ligand organization regulates osteoblast proliferation and differentiation", Nano Letters, 4, pp. 1501-1506 (2004).

23. Yang, S.Y., Kim, E.-S., Jeon, G., et al. "Enhanced adhesion of osteoblastic cells on polystyrene films by independent control of surface topography and wettability", Materials Science and Engineering: C, 33, pp. 1689-1695 (2013).

24. Kontziampasis, D., Bourkoula, A., Petrou, P., et al. "Cell array fabrication by plasma nanotexturing", In Bio-MEMS and Medical Microdevices, p. 87650B (2013).

25. Reznickova, A., Novotna, Z., Kolska, Z., et al. "Enhanced adherence of mouse fibroblast and vascular cells to plasma modified polyethylene", Materials Science and Engineering: $C, \mathbf{5 2}$, pp. 259-266 (2015).

26. Islam, M., Atmaramani, R., Mukherjee, S., et al. "Enhanced proliferation of PC12 neural cells on untreated, nanotextured glass coverslips", Nanotechnology, 27, p. 415501 (2016).
27. Marcatti Amarú Maximiano, W., Marino Mazucato, V., Tambasco de Oliveira, P., et al. "Nanotextured titanium surfaces stimulate spreading, migration, and growth of rat mast cells", Journal of Biomedical Materials Research Part A, 105, pp. 2150-2161 (2017).

28. Yiannakou, C., Simitzi, C., Manousaki, A., et al. "Cell patterning via laser micro/nano structured silicon surfaces", Biofabrication, 9, p. 025024 (2017).

29. Wang, L.. Asghar, W., Demirci, U., et al. "Nanostructured substrates for isolation of circulating tumor cells", Nano Today, 8, pp. 374-387 (2013).

30. Wang, S., Wang, H., Jiao, J., et al. "Three-dimensional nanostructured substrates toward efficient capture of circulating tumor cells", Angewandte Chemie, 121, pp. 9132-9135 (2009).

31. Islam, M., Sajid, A., Mahmood, M.A.I., et al. "Nanotextured polymer substrates show enhanced cancer cell isolation and cell culture", Nanotechnology, 26, p. 225101 (2015).

32. Hosseini, S.A., Abdolahad, M., Zanganeh, S., et al. "Nanoelectromechanical chip (NELMEC) combination of nanoelectronics and microfluidics to diagnose epithelial and mesenchymal circulating tumor cells from leukocytes", Small, 12, pp. 883-891 (2016).

33. Dou, X., Li, P., Jiang, S., et al. "Bioinspired hierarchically structured surfaces for efficient capture and release of circulating tumor cells", ACS Applied Materials \& Interfaces, 9, pp. 8508-8518 (2017).

34. Tserepi, A., Gogolides, E., Bourkoula, A., et al. "Plasma nanotextured polymeric surfaces for controlling cell attachment and proliferation: a short review", Plasma Chemistry and Plasma Processing, 36, pp. 107-120 (2016).

35. Ellinas, K., Tserepi, A., and Gogolides, E. "Durable superhydrophobic and superamphiphobic polymeric surfaces and their applications: A review", Advances in Colloid and Interface Science, 250, pp. 132-157 (2017).

36. Variola, F., Vetrone, F., Richert, L., et al. "Improving biocompatibility of implantable metals by nanoscale modification of surfaces: an overview of strategies, fabrication methods, and challenges", Small, 5, pp. 996-1006 (2009).

37. Zhukova, Y. and Skorb, E.V. "Cell guidance on nanostructured metal based surfaces", Advanced Healthcare Materials, 6, p. 1600914 (2017).

38. Rajnicek, A., Britland, S., and McCaig, C. "Contact guidance of CNS neurites on grooved quartz: influence of groove dimensions, neuronal age and cell type", Journal of Cell Science, 110, pp. 2905-2913 (1997).

39. Mahmood, M.A.I., Wan, Y., Islam, M., et al. "Micro+ nanotexturing of substrates to enhance ligand-assisted cancer cell isolation", Nanotechnology, 25, p. 475102 (2014).

40. Thibaud, C., Koubassov, V., De Koninck, P., et al. "Destruction of polymer growth substrates for cell cultures in two-photon microscopy", Journal of Microscopy, 220, pp. 120-127 (2005). 
41. Lee, J.N., Jiang, X., Ryan, D. et al. "Compatibility of mammalian cells on surfaces of poly (dimethylsiloxane)", Langmuir, 20, pp. 11684-11691 (2004).

42. Vandrovcova, M., Hanus, J., Drabik, M., et al. "Effect of different surface nanoroughness of titanium dioxide films on the growth of human osteoblast-like MG63 cells", Journal of Biomedical Materials Research Part A, 100A, pp. 1016-1032 (2012).

43. Ho, J. "Cell adhesion to biomaterials. The role of several extracellular matrix components in the attachment of non-transformed fibroblasts and parenchymal cells", ASAIO Trans., 33, pp. 66-74 (1987).

44. Wang, L., Sun, B., Ziemer, K.S., et al. "Chemical and physical modifications to poly(dimethylsiloxane) surfaces affect adhesion of Caco-2 cells", Journal of Biomedical Materials Research Part A, 93A, pp. 12601271 (2010).

45. Draux, F., Jeannesson, P., Beljebbar, A., et al. "Raman spectral imaging of single living cancer cells: a preliminary study", Analyst, 134, pp. 542-548 (2009).

46. Bhatt, S., Pulpytel, J., Mirshahi, M., et al. "Catalyst-free plasma-Assisted copolymerization of poly ( $\varepsilon$-caprolactone)-poly(ethylene glycol) for biomedical applications", ACS Macro Letters, 1, pp. 764-767 (2012).

47. Bhatt, S., Pulpytel, J., Mirshahi, M., et al. "Nano thick poly( $\varepsilon$-caprolactone)-poly(ethylene glycol) coatings developed by catalyst-free plasma assisted copolymerization process for biomedical applications", RSC Advances, 2, pp. 9114-9123 (2012).

48. Department of Cell Bank, Pasteur Institute of Iran (2016); Available: http://en.pasteur.ac.ir/pages. aspx?id $=823$

49. Maioli, E., Torricelli, C., Fortino, V., et al. "Critical appraisal of the MTT assay in the presence of rottlerin and uncouplers", 11, pp. 227-240 (2009).

50. Carriere, B., Deville, J.P., Brion, D., et al. "Xray photoelectron study of some silicon-oxygen compounds", Journal of Electron Spectroscopy and Related Phenomena, 10, pp. 85-91 (1977).

51. Sharma, V., Dhayal, M., Govind, et al. "Surface characterization of plasma-treated and PEG-grafted PDMS for micro fluidic applications", Vacuum, 81, pp. 1094-1100 (2007).

52. Oehr, C. "Plasma surface modification of polymers for biomedical use", Nuclear Instruments and Methods in Physics Research Section B: Beam Interactions with Materials and Atoms, 208, pp. 40-47 (2003).

53. Wang, N., Tytell, J.D., and Ingber, D.E. "Mechanotransduction at a distance: mechanically coupling the extracellular matrix with the nucleus", Nature Reviews Molecular Cell Biology, 10, p. 75 (2009).

54. Shamloo, A., Manchandia, M., Ferreira, M., et al. "Complex chemoattractive and chemorepellent Kit signals revealed by direct imaging of murine mast cells in microfluidic gradient chambers", Integrative Biology, 5, pp. 1076-1085 (2013).
55. Shamloo, A., Heibatollahi, M., and Mofrad, M.R. "Directional migration and differentiation of neural stem cells within three-dimensional microenvironments", Integrative Biology, 7, pp. 335-344 (2015).

56. Dalby, M.J. "Topographically induced direct cell mechanotransduction", Medical Engineering \& Physics, 27, pp. 730-742 (2005).

57. Shamloo, A., Mohammadaliha, N., Heilshorn, S.C., et al. "A comparative study of collagen matrix density effect on endothelial sprout formation using experimental and computational approaches", Annals of Biomedical Engineering, 44, pp. 929-941 (2016).

58. Le Clainche, C. and Carlier, M.-F. "Regulation of actin assembly associated with protrusion and adhesion in cell migration", Physiological Reviews, 88, pp. 489-513 (2008).

59. Davidson, P.M., Özçelik, H., Hasirci, V., et al. "Microstructured surfaces cause severe but nondetrimental deformation of the cell nucleus", Advanced Materials, 21, pp. 3586-3590 (2009).

60. Davidson, P.M., Fromigué, O., Marie, P.J., et al. "Topographically induced self-deformation of the nuclei of cells: dependence on cell type and proposed mechanisms", Journal of Materials Science: Materials in Medicine, 21, pp. 939-946 (2010).

61. Ermis, M., Akkaynak, D., Chen, P., et al. "A high throughput approach for analysis of cell nuclear deformability at single cell level", Scientific Reports, 6, p. 36917 (2016).

62. Richert, L., Vetrone, F., Yi, J.H., et al. "Surface nanopatterning to control cell growth", Advanced $M a$ terials, 20, pp. 1488-1492 (2008).

\section{Biographies}

Amir Shamloo is an Associate Professor of the Mechanical Engineering Department at Sharif University of Technology, Tehran, Iran. His research interests are the microfluidic devices, bionanotechnology and molecular modeling.

Maryam Alsadat Rad received her PhD from UTM Malaysia. Her current research focus is the biological applications of microfluidic devices.

Mohamad Taghi Ahmadian is currently a Professor of the Mechanical Engineering Department at Sharif University of Technology, Tehran, Iran. His current research interests are the biological system dynamics, microfluidic devices and nanotechnology.

Leyla Amirifar is currently a $\mathrm{PhD}$ candidate in Mechanical Engineering Department at Sharif University of Technology, Tehran, Iran. Her current research focus is the biological applications of microfluidic devices. 